Quarterly Reviews of

Biophysics

cambridge.org/qrb

\section{Corrigendum}

Cite this article: Klump $\mathrm{HH}$, Völker J, Breslauer KJ (2020). Energy mapping of the genetic code and genomic domains: implications for code evolution and molecular Darwinism - CORRIGENDUM. Quarterly Reviews of Biophysics 53, e14, 1-2. https://doi.org/ $10.1017 /$ S0033583520000116

\title{
Energy mapping of the genetic code and genomic domains: implications for code evolution and molecular Darwinism - CORRIGENDUM
}

\section{Horst H. Klump ${ }^{1}$, Jens Völker ${ }^{2}$ and Kenneth J. Breslauer ${ }^{2,3}$}

\footnotetext{
${ }^{1}$ Department of Molecular and Cell Biology, University of Cape Town, Private Bag, Rondebosch 7800, South Africa; ${ }^{2}$ Department of Chemistry and Chemical Biology, Rutgers, The State University of New Jersey, 610 Taylor Rd, Piscataway, NJ 08854, USA and ${ }^{3}$ Rutgers Cancer Institute of New Jersey, New Brunswick, NJ 08901, USA
}

DOI: $10.1017 /$ S0033583520000098 First published online by Cambridge University Press, 4 November 2020.

The original Fig. 2 in this paper contains a single inconsequential typo in each of the RRR, YRR, and YRY cubes. Specifically, the vertex labeled GCA in the RRR cube should read AAA, the vertex labeled GCA in the YRR cube should read CGA, and the vertex labeled GCA in the YRY cube should read CAT. These typos had no impact on our analyses. For clarity, Fig. 2 is reproduced below with these typos corrected.

\section{CAMBRIDGE UNIVERSITY PRESS}




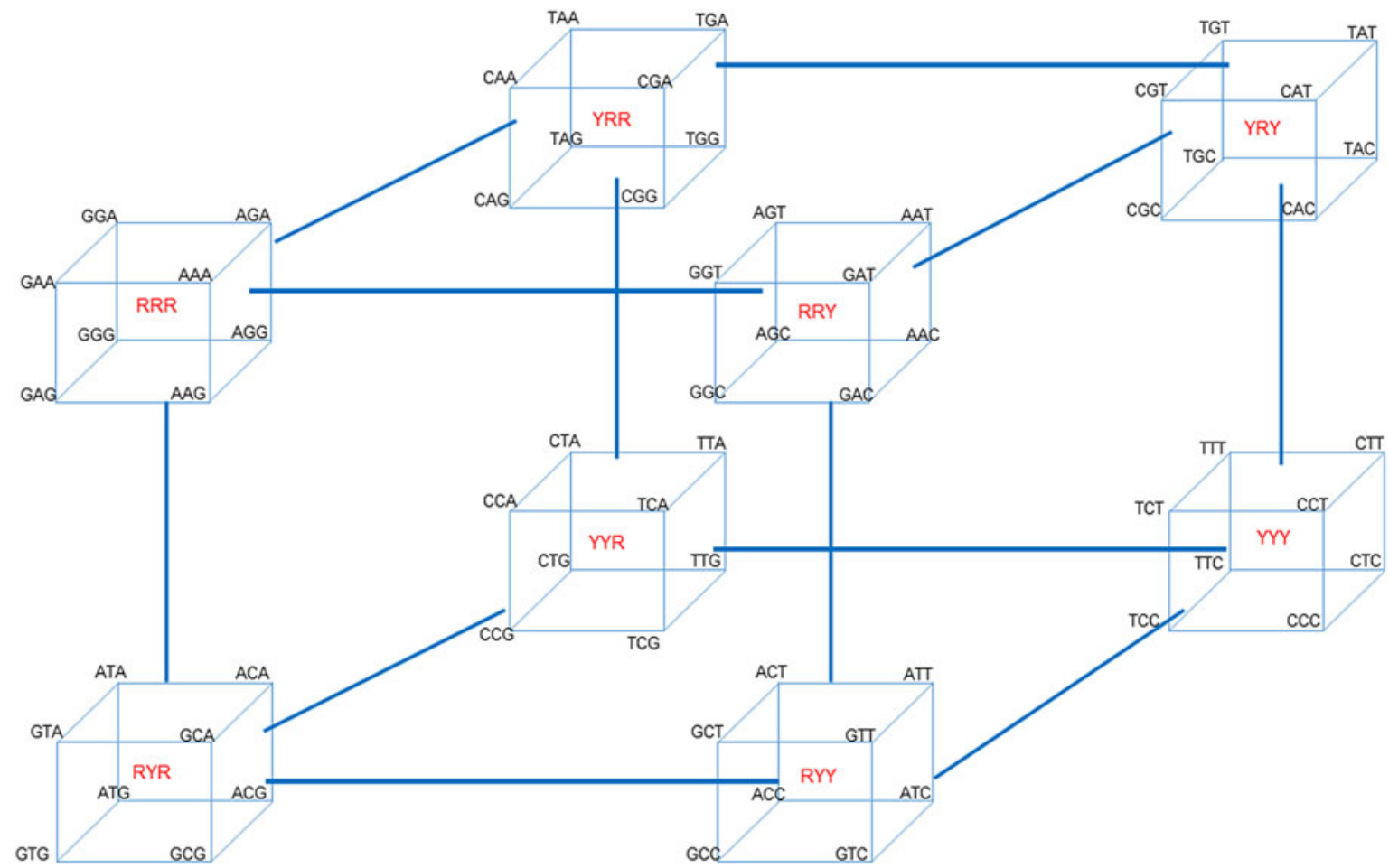

Fig. 2. The hypercube of all eight cube octet sequence classes (shown in red) located at each apex of the hypercube, illustrating the interconnectedness of the cycles associated with the full cascade of codon interconversions via sequential site changes. Transition mutations occur within a cube, while transversion mutations link one cube to another.

\section{Reference}

Klump HH, Völker J and Breslauer KJ (2020) Energy mapping of the genetic code and genomic domains: implications for code evolution and molecular Darwinism. Quarterly Reviews of Biophysics 53, e11, 1-8. 